\title{
ZAPAŽANJA ZAPOSLENIKA - UVJET UNAPREDIVANJA KULTURE ZAŠTITE NA RADU
}

UDK 331.45:65.12.22

PRIMLJENO: 10.1 .2018 .

PRIHVAĆENO: 4.6 .2018

\begin{abstract}
SAŽETAK: U sprečavanju ozljeda na radu zakon predviđa primjenu priznatih pravila struke, te u praksi provjerene načine pomoću kojih se otklanjaju ili smanjuju rizici na radu.

Safety Hazard Observation Cards (SHOC) dokazano je korisno sredstvo za povećanje svijesti zaposlenika i pozornosti o nesigurnim radnjama i nesigurnim uvjetima. Bez obzira na to, u hrvatskoj praksi teško je uvjeriti zaposlenike da zapišu svoja zapažanja i potpišu ih.

Tijekom godina u Podružnici Saipem SpA u Republici Hrvatskoj uočena je nevoljkost zaposlenika spram ispunjavanja SHOC-kartica. Kako bi se motivirali zaposlenici, organizirana su događanja s iskonstruiranim opasnostima koje su radnici u određenom roku trebali pronaći te ih zapisati i opisati na za to predviđenim formularima/karticama. Zaposleniku koji je prvi prepoznao sve "iskonstruirane opasnosti" dodijeljena je nagrada.

Tijekom tih događanja broj napisanih SHOC-kartica ne samo da je nadmašio njihovu godišnju "proizvodnju", nego je i pomogao da se prepoznaju i otklone mnoge druge opasnosti, a zaposlenici su sa zadovoljstvom sudjelovali.

Događaj je organiziran nekoliko puta godišnje kako bi se poboljšala svijest o važnosti popunjavanja SHOC-kartica i ojačali napori za promjenu kulture sigurnosti na radu.
\end{abstract}

Ključne riječi: SHOC-kartica, kultura sigurnosti na radu, Saipem S.p.A. Podružnica u Republici Hrvatskoj

\section{UVOD}

Hrvatski Zakon o zaštiti na radu jasno definira prava i obveze kako poslodavca, tako i radnika glede sprečavanja, odnosno smanjivanja rizika od nastanka ozljeda na radu, profesionalnih bolesti, bolesti u vezi s radom, te ostalih štetnih posljedica za radnike. Štoviše, u članku 5. spomenutog zakona navodi se da su život, zdravlje i očuvanje radne sposobnosti vrijednosti od posebnog društvenog interesa u Republici Hrvatskoj, te da je zaštita na radu od javnog interesa, dakle, briga i interes svih. Ona se ostvaruje

*Mr. sc. Frano Mika, dr. med. (frano.mika@saipem.com), David Dunger, struč. spec. ing. sec., SAIPEM S.p.A. Podružnica u Republici Hrvatskoj, Alda Colonnella 2, 51000 Rijeka. primjenom osnovnih, posebnih i priznatih pravila zaštite na radu u skladu s općim načelima prevencije, ali i onih priznatih pravila zaštite na radu koja podrazumijevaju i u praksi provjerene načine, pomoću kojih se otklanjaju ili smanjuju rizici na radu.

Pored inih obveza predviđenih ovim Zakonom, poslodavac mora izraditi i procjenu rizika, u izradi koje moraju biti uključeni i radnici, a propusti učinjeni u postupku ne ekskulpiraju ga od odgovornosti.

S druge strane, obveze radnika su obavljati poslove s dužnom pažnjom, te pri tome voditi računa o svojoj sigurnosti i zaštiti zdravlja, kao i sigurnosti i zaštiti zdravlja ostalih radnika koje mogu ugroziti njegovi postupci ili propusti 
na radu, odnosno prije početka rada pregledati mjesto rada, te o uočenim nedostacima izvijestiti poslodavca ili njegovog ovlaštenika. Jednako tako njegova je obveza odmah obavijestiti poslodavca, ili drugu za to zaduženu osobu o svakoj situaciji ili uočenom nedostatku koju smatra značajnim i izravnim rizikom za sigurnost i zdravlje. Radnik ima pravo odbiti raditi ako mu izravno prijeti rizik za život i zdravlje, sve dok poslodavac ne poduzme korektivne mjere.

Iz navedenog očito je da je zakonodavac jasno definirao odgovornosti poslodavca pri određivanju mjera zaštite na radu i njihovom provođenju, kao i aktivnu ulogu radnika, u uočavanju i uklanjanju svih opasnosti i rizika na poslu, kako tijekom procesa procjene rizika, tako i u svakom trenutku kad uoči neku, do tada neprepoznatu, odnosno novonastalu, opasnost od ozljeda na radu i profesionalnih bolesti, bolesti u vezi $\mathrm{s}$ radom, te ostalih štetnih posljedica za sebe i/ili ostale radnike.

Pod pretpostavkom da je poslodavac ispunio sve svoje obveze predviđene Zakonom o zaštiti na radu, njegovim nadopunama, te odnosnim podzakonskim aktima, postavlja se pitanje koliko je danas u Hrvatskoj radnik/djelatnik spreman aktivno sudjelovati u oblikovanju kulture zaštite na radu? To znači ukazivati na opasnosti na radnom mjestu, sudjelovati u procjeni rizika te pismenim prijavljivanjem svake možebitne nepravilnosti u sustavu zaštite na radu, odnosno (nove) opasnosti koju je uočio u procesu rada ili ponašanju drugih osoba na radu, a koje nisu na odgovarajući način uklonjene ili odnosni rizik smanjen.

Svaka kultura može se definirati kao „način na koji mi radimo stvari ovdje", a njezina promjena, pa tako i promjena kulture zaštite na radu, iziskuje dulje vrijeme i naporan rad onih koji je žele mijenjati (Mika i sur., 2017.).

Kada se govori o "kulturi zaštite na radu“ (Safety culture), ne smije ju se miješati s „ozračjem zaštite na radu“ (Safety climate). Prema brojnim akademskim radovima (Safety culture..., 2018., Deal with it training, 2018.), ozračje zaštite na radu je skup vjerovanja, vrijednosti i percepcije o sigurnosti koje se dijele unutar određene skupine u nekom određenom trenutku, obično kao posljedica nedavnih događaja, uspjeha ili neuspjeha, obilježavanja dugih razdoblja bez ozbiljnijih nesreća na radu ili nakon teških nesreća, proslava i slično. Kultura zaštite na radu rabi se kao pojam koji se odnosi na ponašanja i tradiciju za dulje razdoblje. Njezino stvaranje obično traje dugo vremena, te se ovaj povijesni kontekst koncepta razlikuje od ozračja (Deal with it training, 2018., Guldenmund, 2000.).

\section{CILJ}

Uvjereni da se kultura zaštite na radu može osnažiti isključivo suradnjom svih čimbenika uključenih u obavljanje poslova i radnih zadataka, cilj nam je bio povećati, njihovim konkretnim zapažanjima, utjecaj i doprinos što većeg broja zaposlenika, osigurati da taj doprinos bude trajan te učiniti tečnijim i lakšim izravan dijalog na tu temu između zaposlenika i rukovoditelja.

\section{METODOLOGIJA}

\section{Inicijative SAIPEM-a - incentive scheme $\mathbf{i}$ SHOC}

Kako bi potaknuo sudjelovanje, kako rukovoditelja, tako i zaposlenika na svim razinama u procesu jačanja kulture zaštite na radu, a time radni okoliš učinio sigurnijim, Saipem je tijekom zadnjih 10-ak godina proveo niz inicijativa (Mika i sur., 2017.). One uključuju, Leadership in Health and Safety Program, Keep your hands safe, We want Zero itd. Neke mjere su uspostavljene i određene putem korporativnih dokumenata, poput standarda, operativnih procedura, radnih uputa itd., s ciljem da se na svim radnim lokacijama, bez obzira u kojem se dijelu svijeta nalaze i koje se djelatnosti na njima obavljaju, te mjere i primijene. Dva dokumenta su u ovom kontekstu posebno značajna, a to su HSE Incentive Scheme (WI-SPA-HSE-025-E) i Safety and Hazard Observations (WI-SPA-HSE-026-E).

Poticajne sheme u zaštiti na radu (HSE Incentive scheme) sastoje se od provedbe programa 
unutar kompanije s ciljem povećanja svijesti o problemima zaštite na radu. Za najbolje ostvarene rezultate, koji se utvrđuju analizom unaprijed određenih parametara, dodjeljuju se individualne ili kolektivne nagrade. Iz procesa je isključeno osoblje zaposleno u službi zaštite na radu u bilo kojem svojstvu (Saipem..., 2018.).

Što se pak Safety Hazard Observation Cards (SHOC) tiče, osmišljene su kao obrazac, sastavni dio sustava za prepoznavanje, izvješćivanje, evidentiranje, praćenje i upravljanje opasnostima i/ili drugim aspektima u vezi sa zaštitom na radu, koje ispunjavaju zaposlenici ili posjetioci nakon što su uočili nepravilnosti ili potencijalne opasnosti. Putem njih prikupljaju se uglavnom prijedlozi za poboljšanja koja se primjećuju na radnom mjestu (Safety Observation), ali i oni za uklanjanje nesigurnih radnji i/ili nesigurnih radnih uvjeta (Hazard Observations). Cilj je njihovim korištenjem povećati svijest zaposlenika o problemima zaštite na radu, kao i njihovu predanost toj istoj problematici. Ispunjavanjem kartica i korištenjem SHOC-sustava očekuje se da sami zaposlenici pridonesu što sigurnijem radnom mjestu, a time i smanjenju ozljeda na radu. Osnovna razlika između usmene prijave nepravilnosti i predaje uredno popunjene SHOC-kartice jest „sljedivost“ (traceability). Jednom popunjena i predana Službi zaštite na radu, odnosno neposrednom rukovoditelju, SHOC-kartica ulazi u sustav, te se ista mora evidentirati, po njoj se mora postupiti, nedostaci ukloniti, odnosno poboljšanja provesti, a o svim poduzetim radnjama poslodavac, ako je potpisana, mora izvijestiti potpisnika (Saipem..., 2018.).

Kao što je i predviđeno, ili bolje rečeno dopušteno korporacijskim dokumentima, Saipem SpA Podružnica u Republici Hrvatskoj (SACRO) spojio je dvije inicijative, te uveo u svoj sustav godišnje poticajne sheme zaštite na radu spram pojedinaca koji su se istaknuli u provođenju, promicanju i poboljšanju sustava zaštite na radu, a jedan od elemenata koji je ulazio u sveukupnu ocjenu bio je i broj, te kvaliteta ispunjenih i predanih SHOC-kartica.

No, i pored, za tu priliku i namjenu značajnih, sredstava osiguranih za dobitnika nagrade poticajne sheme, odaziv zaposlenika u obliku predaje SHOC-kartica bio je ispod očekivanja usprkos motivacijskim porukama koje su na svakom sastanku posvećenom zaštiti na radu stizale od samog vrha kompanije. Zabrinuti da strah od prividnog "prokazivanja“ kolega ili kompanije nije uzrok slabom odazivu, prihvaćena je i anonimnost, odnosno neobveza potpisivanja kartice. No, i dalje je odaziv bio slab, a zaposlenici nisu bili voljni ispunjavati SHOC-kartice.

\section{IZGRADNJA KULTURE KROZ ZABAVU}

U sklopu svojih radnih aktivnosti SACRO je donedavno imao i laboratorij za zavarivanje (Welding Workshop Rijeka - WWR) u kojem su se u uvjetima radionice testirale metode zavarivanja, osposobljavali i certificirali zavarivači, te pronalazile $\mathrm{i}$ isprobavale nove tehnike zavarivanja i kontrole zavara. lako se svijest o sigurnosti zaposlenika WWR-a neprekidno poboljšavala, te je već bila dostigla razmjerno visoku razinu, kultura zapisivanja i prijavljivanja uočenih opasnosti na radnom mjestu pokazivala je suprotan trend i broj SHOC-kartica se smanjivao. lako nigdje nije naznačena obveza ispunjavanja SHOC-kartica, rukovodstvo kompanije, kao i drugi stručnjaci (Karish, 2018.), smatralo je da su one dobar pokazatelj proaktivnosti, koncentriranosti i kulture zaposlenika spram zaštite na radu. Odjel zaštite na radu SACRO-a odlučio je pronaći drugačiji i učinkovitiji način poticanja kulturnih promjena, te motivirati zaposlenike da posvete više pozornosti aktivnom sudjelovanju u kreiranju zdravog i sigurnog radnog mjesta. Tijekom sastanka Uprave, na okvirni prijedlog tadašnjeg direktora, a uz suglasnost svih prisutnih, prionulo se organiziranju "SHOC-događaja“. Ideja je bila uključiti zaposlenike WWR-a u traženje "iskonstruiranih opasnosti" na radnom mjestu koje bi prethodno postavili zaposlenici Odjela zaštite na radu.

Događaj se organizirao na način da su djelatnici Odjela zaštite na radu tijekom pauze za ručak postavili tri "iskonstruirane opasnosti" pokrivajući podjednako sva područja gdje se izvodio proces rada. Sve „opasnosti“ su fotografirane, a fotografije stavljene u omotnicu kao dokaz koji je prikazan na kraju natjecanja. Zadatak sudionika bio je da u roku od 30 minuta, obilazeći prostor laboratorija, pronađu „iskonstruirane 
opasnosti“, ispune SHOC-kartice, te ih predaju stručnjaku zaštite na radu. Svaki sudionik mogao je ispisati neograničeni broj kartica, a pobjednik je bio onaj koji u najkraćem vremenu pronađe i prijavi sve tri "iskonstruirane opasnosti“. Nagrada pobjedniku bio je novčani bon. Nakon povratka radnika s ručka, voditelj Laboratorija objasnio je zaposlenicima, čije je sudjelovanje u ovom događaju bilo u cijelosti dobrovoljno, pravila natjecanja te je „potraga“ mogla započeti. Ovakav događaj ponovljen je dva puta, uz naravno, uvijek nove "iskonstruirane opasnosti".

Primjeri „iskonstruiranih opasnosti“ su nepričvršćena plinska boca u području zavarivanja (slika 1), drvena paleta s virećim čavlima postavljenim na platformu mobilne dizalice neposredno iznad ljestava (slika 2), jakna postavljena na aparat za gašenje požara, što je otežavalo pristup (slika 3).

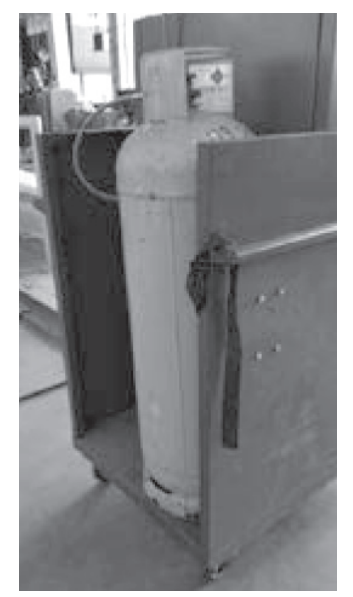

Slika 1. Nepričvršćena plinska boca u području zavarivanja

Figure 1. Unfastened gas tank during welding

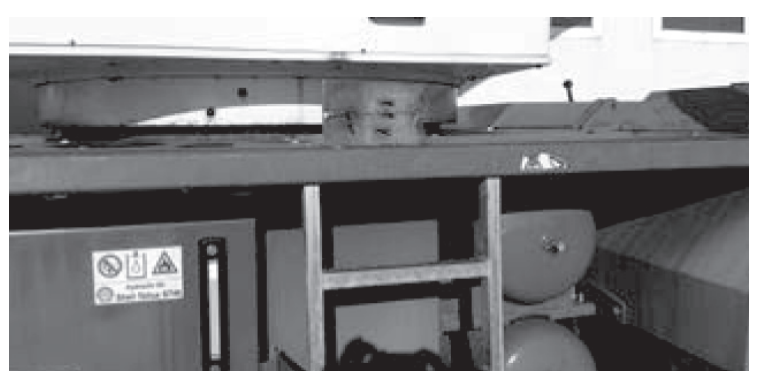

Slika 2. Neispravno postavljena drvena paleta

Figure 2. Incorrectly placed wood pallete

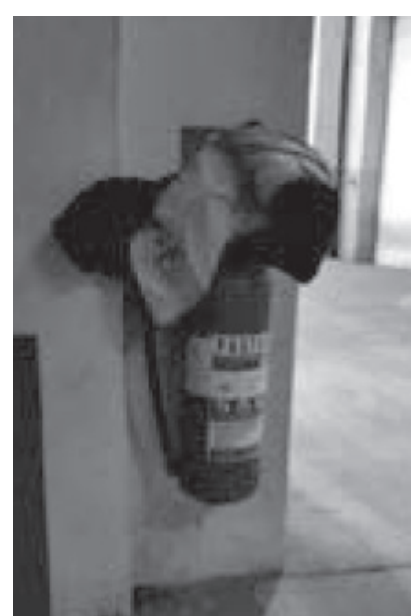

Slika 3. Odložena jakna na aparat za gašenje požara

Figure 3. Jacket left on fire extinguisher

Kako je cilj akcije pojačati i svijest o zaštiti okoline uključujući i diferencirano sakupljanje otpada, a kompanija ima ISO 14001 certifikat, odlučeno je da jedna „iskonstruirana“ nepravilnost bude vezana i s očuvanjem okoliša. Izabrano je nepravilno odlaganje otpada (slika 4).

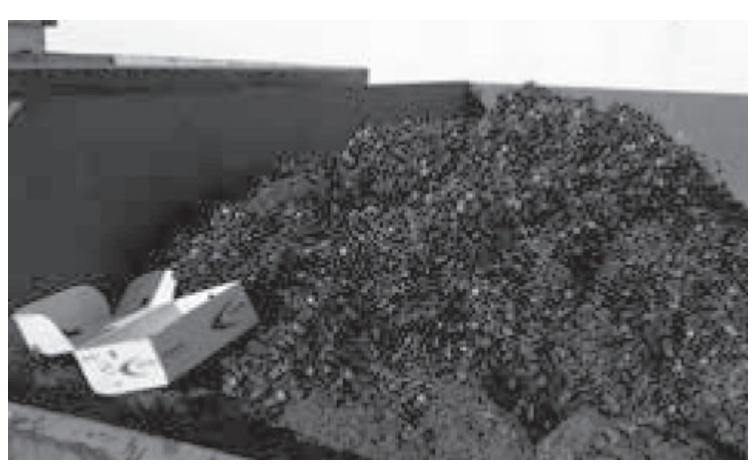

Slika 4. Nepravilno odlaganje otpada

Figure 4. Incorrect waste disposal

Po završetku „natjecanja“ zaposleniku koji je prvi pronašao sve tri iskonstruirane opasnosti/ nepravilnosti, voditeljica laboratorija je uz malu svečanost predala zasluženu nagradu. Tijekom svečanosti prisutni zaposlenici, voditelji službe, te djelatnici Odjela zaštite na radu zajedno su razgovarali o „iskonstruiranim“ i drugim pronađenim opasnostima, preispitali ih i utvrdili zašto je određena situacija opasna, te koje bi bile moguće posljedice ako se ista ne otkloni. 


\section{REZULTATI}

Analiza SHOC-kartica, koje su napisali sudionici, pokazala je više nego zadovoljavajuće rezultate. Sudionici, njih 30-ak dakle gotovo svi zaposleni u Laboratoriju za zavarivanje, sveukupno su ispunili i predali 67 SHOC-kartica, dok ih je prethodne godine tijekom cijele godine predano ukupno 7 (sedam). Autori smatraju da je jedna od važnijih činjenica proizašla iz ovih događanja, odnosno da je većina uključenih osoba pronašla stvarne opasnosti koje prethodno nije konstruirao tim zaštite na radu, ali do tada nisu bile prijavljene putem SHOC-kartica, niti na bilo koji drugi način.

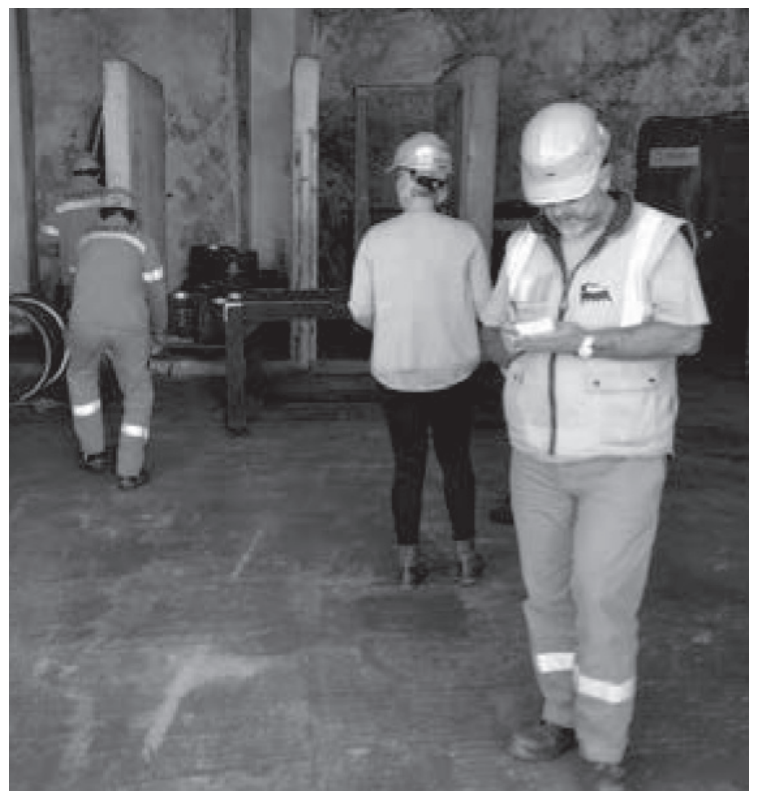

Slika 5. Zaposlenici u potrazi za opasnostima

Figure 5. Employees detecting hazards

U razgovoru sa zaposlenicima nakon svakog od ovih događaja, autori su saznali da je velika većina s užitkom sudjelovala u njima, da ih je ovaj oblik aktivnosti potaknuo na razmišljanje i detaljnije promatranje radne okoline, da su se na neki način oslobodili "straha“od ispunjavanja SHOC-kartica. Odličnim su ocijenili i razgovore o opasnostima i njihovom vođenju nakon događanja. Posebno je bila cijenjena nazočnost voditelja službi na događanjima, te njihovo aktivno sudjelovanje u razgovorima. Svi sudionici izrazili su želju i spremnost za sudjelovanje na sličnim događanjima i u budućnosti.
Autori su svjesni da dva događaja nisu u cijelosti mogla kod zaposlenika promijeniti kulturu aktivnog pristupa diskusiji o zaštiti na radu, odnosno o mjerama za njezino poboljšanje, poglavito ako su među sugovornicima nadređeni i rukovoditelji. No, sigurno da su vrata takvom pristupu brige o sebi i drugima odškrinuta, da su zaposlenici, a i rukovoditelji pokazali spremnost i otvorenost spram promjena, te da je podizanje svijesti i samosvijesti najbolji način promjene ponašanja. Pri tome novčana nagrada ne mora biti i nije glavni motivirajući faktor akcije pojedinca. $U$ tome rukovoditelji moraju sudjelovati i preuzeti vodeću ulogu. Zajedno s rukovodstvom kompanije Odjel zaštite na radu planira daljnju organizaciju događanja ovog tipa.

\section{ZAKLJUČAK}

Briga o zaštiti na radu prvenstveno je dužnost poslodavca, koji osim što mora poštovati sve zakonske i podzakonske akte, može u svojem djelovanju primijeniti i pozitivna iskustva iz prakse. Jednako tako u provođenju, poštovanju i u unapređivanju mjera zaštite na radu i zaposlenici imaju svoje obveze. Kultura zaštite na radu može se i treba popraviti zajedničkim radom svih struktura unutar kompanije, koristeći pri tome zakonsku regulativu, ali i alate, npr. poticajne sheme odnosno ispunjavanje SHOC-kartica.

lako su se SHOC-kartice ispunjene od zaposlenika u svijetu pokazale kao dobar indikator kulture zaštite na radu, te su pridonijele sigurnijim radnim mjestima, obveza njihovog ispunjavanja i postavljanje ciljeva glede njihovog broja, kao što je praksa u nekim kompanijama, nije se pokazala učinkovitom u dugoročnoj promjeni ponašanja i odnosa prema zaštiti na radu.

No, kada se slične aktivnosti osmisle kao svojevrsno natjecanje među zaposlenicima i igra, onda je odaziv zaposlenika velik, a učinkovitost povećana za nekoliko puta.

Iskustva SACRO-a pokazuju da zabavniji, neobvezujući, ali ipak trajan i usredotočen pristup promjeni kulture zaštite na radu putem zapažanja zabilježenih na SHOC-karticama daje dobre rezultate, poglavito $\mathrm{u}$ interakciji s bezrezervnom podrškom i konkretnim akcijama rukovodstva. 


\section{LITERATURA}

Deal with it training, dostupno na: http://www. dealwithittraining.co.uk/the-difference-betweensafety-culture-and-safety-climate/, pristupljeno: 5.1.2018.

Guldenmund, FW.: The nature of safety culture: A review of theory and research, Safety Science, 34, 2000., No1-3, pp215-257.

Karish, JM.: Starting to get STOPTM Right (Behaviour Based Safety - One Drilling Contractor's Journey...), dostupno na: http://www.iadc.org/ conferences/AP1/John\%20Karish\%20STOP.pdf pristupljeno: 5.1.2018.

Mika F. i sur.: Liderstvo i intervencije u ponašanju kao put ka unapređenju kulture sigurnosti na radu, Sigurnost, 59, 2017., 3, 255-262.
Safety Culture: $A$ review of the literature HSL/2002/25, dostupno na http://www.hse.gov. uk/research/hsl_pdf/2002/hsl02-25.pdf, pristupljeno: 5.1.2018.

Saipem SpA Work Instruction: HSE Incentive Scheem, document code WI-SPA-HSE-025-E, issued 2011, dostupno na: http://sharepoint. saipemnet.saipem.intranet/Europe/SAIPEM $\% 20$ SpA/DOCUMENT\%20SYSTEM/TVN/HSE/Pdf/WISPA-HSE-025-I-R01.pdf, pristupljeno: 5.1.2018.

Saipem SpA Work Instruction Safety and Hazard observations (WI-SPA-HSE-026-E, issued 2011, dostupno na: http://sharepoint.saipemnet. saipem.intranet/Europe/SAIPEM\%20SpA/DOCUMENT\%20SYSTEM/TVN/HSE/Pdf/WI-SPA-HSE026-E-R01.pdf, pristupljeno: 5.1.2018

Zakon o zaštiti na radu, N.N., br. 71/14., $118 / 14$.

\section{SAFETY HAZARD OBSERVATON - A CONDITION FOR IMPROVEMENT OF SAFETY AT WORK CULTURE}

SUMMARY: In preventing injury at work, the law provides for the application of recognized professional rules and in practice proven ways of eliminating or reducing workplace risks.

Safety Hazard Observation Cards (SHOC) have proven to be a useful tool to increase employees' awareness and attention to unsafe actions and unsafe conditions. However, in Croatian practice, it is difficult to persuade employees to write down their observations and sign them.

Over the years, in the Saipem SpA Croatian Branch, we encountered employees' reluctance towards filling the SHOC-cards. To motivate employees, we have organized events in which we set up hazards that employees should locate in the allotted time, and write and describe them on the forms, i.e. cards provided for the purpose. The employee who first identified all "set up hazards" was awarded a prize.

During these events, the number of SHOC-cards written not only exceeded their annual "production" but also helped to recognize and eliminate many other hazards, and the employees were pleased to participate.

The event is organized several times a year to enhance awareness of the importance of filling SHOCs and strengthening efforts to change the safety culture.

Key words: SHOC-card, safety culture, Saipem SpA Croatian Branch 